\title{
Predicting the Effects of the Wind Load Direction to Naval Vessels Resistance
}

\author{
Nguyen Duc Hai ${ }^{1,}$, Nguyen Ngoc Dam ${ }^{2}$, Nguyen Vu Giang ${ }^{3}$ \\ ${ }^{1}$ Mechanical Engineering Department, Sao Do University, Hai Duong, Viet Nam \\ ${ }^{2}$ Automobile Department, Sao Do University, Hai Duong, Viet Nam \\ ${ }^{3}$ Faculty of Human Sciences, Macquarie University, Sydney, Australia
}

Email address:

shipbuilding_dta10@yahoo.com (N. D. Hai)

${ }^{*}$ Corresponding author

To cite this article:

Nguyen Duc Hai, Nguyen Ngoc Dam. Predicting the Effects of the Wind Load Direction to Naval Vessels Resistance. International Journal of Transportation Engineering and Technology. Vol. 5, No. 1, 2019, pp. 18-24. doi: 10.11648/j.ijtet.20190501.13

Received: April 18, 2019; Accepted: May 31, 2019; Published: June 18, 2019

\begin{abstract}
The influence of wind loads on the operation of naval vessels must be thoroughly considered in the design process. However, nowadays the evaluation studies on the influence of the wind loads on the naval vessels haven't been adequately interested. These vessels have a windward section relatively large area, which affects the static and dynamic stability of the vessels as well as the cause affecting the ship resistance to fuel consumption. In particular, naval vessels usually operate at high speed, therefore, issue reviews the effect of the wind as well as the angle of the wind direction becomes more important. Thanks to the advancement of computer technology in the analysis of determining the impact of the wind become more quickly, which help reduces the time of testing and saving the cost for built models and allows for more accurate predicting. In this study, the CFD simulation method is applied in order to assess the effect of the wind direction to the resistance of naval vessels resistance in calm water conditions. From the achieved results, the captain made the right decision on the direction of the vessels to ensure maritime safety. Also from the CFD results, ship designers have plans to arrange equipment, as well as optimize resistance for these vessels.
\end{abstract}

Keywords: Naval Vessels, Aerodynamic Drag, CFD Method, Ship's Resistance, Air Resistance

\section{Introduction}

In this present study, we have proposed a new CFD application study to estimating naval vessels wind resistance as well as assessing the effects of the angle of the wind direction[1, 2]. From which resistance thereby to help the naval vessels designers have evaluation static and dynamic stability for this ship type [3]. Traditional study methods including many experiments test models, experience formulas and numerical simulations [4]. CFD analysis methods have been developed and applied more and more to solve marine hydrodynamics problems in recent years. Viscosity liquid may be considered adequate and non-linear elements can be handled accurately, especially in high Reynold number conditions for high -speed vessels. With the advancements of computer science and the method of calculating numbers are getting more perfect [5]. Nowadays, the effectiveness and accuracy of the CFD methods have improved considerably [6]. The combination of the test model and CFD method analysis is the optimal method to calculation proposed ship resistance [7]. Dang et al. [8] discussed influence factors and number diagrams of hydrodynamic analysis by Fluent.

In this paper, a CFD method has was applied to determine the effect of wind on naval vessels with other angles. The study evaluated the effect of wind impact on the vessels as the highlights article by Ngo Van He et al. is applied CFD in order to evaluate the influence of the upper deck and hull with the angle of the wind direction varies the application of CFD [5, 9]. At the same time in the previous study published [10] we have evaluated and calculated a comprehensive comparison of the ship resistance of multi-purpose oil spill response, the calculation results were compared with the calculation results by the formula experimental as well as compared with data of testing model ships at the national ship test tank-Vietnam 
Shipbuilding Science and Technology Institute. From the assessment shows the reliability of this CFD methods through the calculation and comparison with ship models testing. The previous works have achieved great progress in the development and application CFD methods [11], because of that scientific basis in this paper. We will apply the CFD method in this paper to assess the impact of the wind on naval vessels.

\section{CFD Method Analysis}

CFD numerical simulation is essentially done experiments on the computer simulation. The researchers used the modeling and the appropriate simulation method from that will to obtain close results with the implementation of model test pulls in the test tank as well as the actual observations with the actual operators [12]. The simulation will perform the transfer of physical equations into mathematical equations system fundamentals and then established a mathematical model consisting the approximate equations are solved directly or by iterative methods. From that calculation

method, the results obtained will reach a level required convergence is needed. The results of the CFD numerical method are evaluated as close to the actual vessels when are carefully considered the results of convergence analysis, evaluating the error [13]. Even with the development of highspeed computing approximate calculations can achieve good results. The physical modeling capabilities of ANSYS are widely applied in fluid dynamics calculations. Powerful simulation and powerful solver ensure Fluent has accurate results [14]. Application to modeling turbulent flow analysis of pressure fields, velocity fields using k-epsilon, k-omega model, the Reynolds stress equation.

In this study, the simulation of a viscous single-phase flow field was applied. The equation of continuity and momentum equations of the average Reynold-number and the NavierStokes equation (Rans) is applied in this article can be written as follows:

$$
\nabla \cdot U=0
$$

$$
\frac{\partial \rho U}{\partial t}+\nabla\left[\rho\left(U-U_{g}\right) U\right]=-\nabla p_{d}-g \cdot x \nabla \rho+\nabla \cdot\left(\mu_{\mathrm{eff}} \nabla U\right)+(\nabla U) \cdot \nabla \mu_{\mathrm{eff}}+f_{\sigma}+f_{s}
$$

in which: $U$ stands for velocity field, $\mathrm{p}_{\mathrm{d}}$ is dynamic pressure, $\mathrm{g}$ is the gravity, $\mu_{\text {eff }}$ is effective dynamic viscosity, $f_{\sigma}$ is the surface tension, $\mathrm{f}_{\mathrm{s}}$ tension affects the free surface.

Due to the hull shape characteristics should the flow around the ship's status is a turbulent flow. When tangles occur, it increases the ability to consume energy, heat exchange... Usually, the description of turbulent flow is often very difficult because in the equations specification containing the unknown quantities. Therefore, the turbulent flow equations are integrated and Ansys-Fluent software helps to accurately simulate the physical phenomenon around the hull. In this study, we use the flow model and $\mathrm{k}-\varepsilon$ and are written as follows:

$$
\begin{aligned}
& \frac{\partial(\rho k)}{\partial t}+\frac{\partial\left(\rho k u_{i}\right)}{\partial x_{i}}=\frac{\partial}{\partial x_{i}}\left[\left(\mu+\frac{\mu_{t}}{\sigma_{k}}\right) \frac{\partial_{k}}{\partial x_{i}}\right]+G_{k}+G_{b}-\rho \varepsilon-Y_{M}+S_{k} \\
& \frac{\partial(\rho \varepsilon)}{\partial t}+\frac{\partial\left(\rho \varepsilon u_{i}\right)}{\partial x_{i}}=\frac{\partial}{\partial x_{j}}\left[\left(\mu+\frac{\mu_{t}}{\sigma_{\varepsilon}}\right)\right]+C_{1 \varepsilon} \frac{\varepsilon}{k}\left(G_{k}+C_{3 \varepsilon} G_{b}\right)-C_{2 \varepsilon} \rho \frac{\varepsilon^{2}}{k}+S_{\varepsilon}
\end{aligned}
$$

where: $G_{k}$ is a constant showing the dependence of the formation of the kinetic energy disorder $(\mathrm{k})$ on the variation of the average velocity as follows:

$$
G_{k}=-\rho \overline{u_{i}^{\prime} u_{j}^{\prime}} \frac{\partial u_{j}}{\partial x_{i}}
$$

$\mathrm{G}_{\mathrm{b}}$ is defined as follows:

$$
G_{b}=\beta g_{i} \frac{\mu_{t}}{\operatorname{Pr}_{t}} \frac{\partial T}{\partial x_{i}}
$$

here: $\operatorname{Pr}_{t}$ is the Prantld constant, $\beta$ is the environmental thermal expansion coefficient, $g_{i}$ is the gravitational acceleration component in the direction $i, Y_{M}$ is the coefficient showing the variation in the expansion process compared to the mean:

$$
Y_{M}=2 \rho \varepsilon M_{t}^{2}
$$

$M_{t}=\sqrt{\frac{k}{a^{2}}}$ is the Mach number, a is the sound velocity, $\mu \mathrm{t}$ is the turbulent viscosity coefficient determined as follows:

$$
\mu_{t}=\rho C_{\mu} \frac{k^{2}}{\varepsilon}
$$

\section{Vessel Model and Conditions}

\subsection{Analysis Modeling}

High-speed naval vessels models are studied in this article. The main dimensions and details are shown in Table 1. 3D model of the hull vessel are shown in Table 1, including the bow, stern and hull. In order to get the shape of the ship with the optimal shape, the hull is constructed by combining much-specialized software in the specialized ship design package, which allows reducing the time mesh in the editing process meshing of ship model with Ansys in the next steps. In order for the meshing process to achieve the best quality, the region around the hull surface meshing density monitor is small and smooth over in order to achieve the best accuracy in the calculation process.

Table 1. Main dimensions of naval vessel.

\begin{tabular}{llll}
\hline Dimension design & & & Design \\
\hline Length overall & $\mathrm{L}_{\mathrm{pp}}$ & $\mathrm{m}$ & 44.9 \\
Length water line & $\mathrm{L}_{\mathrm{wp}}$ & $\mathrm{m}$ & 40.1 \\
Breadth module & $\mathrm{B}$ & $\mathrm{m}$ & 8.7 \\
Draught: Fore & $\mathrm{T}_{\mathrm{f}}$ & $\mathrm{m}$ & 1.9 \\
Aft & $\mathrm{T}_{\mathrm{A}}$ & $\mathrm{m}$ & 1.9 \\
\hline
\end{tabular}




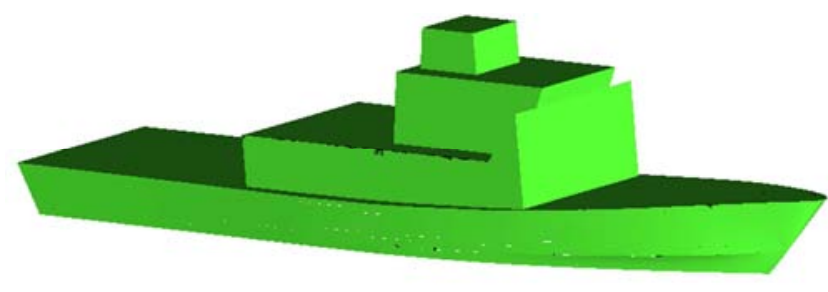

Figure 1. 3D model of the naval vessel.

\subsection{Boundary Conditions}

During the simulation of the most important factor is to set the boundary conditions accordingly, these boundary conditions must be consistent with the actual operation of the vessel. When the simulation will give the same results as the most realistic. Aerodynamic mass is $1,225 \mathrm{~kg} / \mathrm{m}^{3}$ and kinematic viscosity is $1.789 \times 10^{-5} \mathrm{~kg} / \mathrm{ms}$. The value of the gravity acceleration is $9,81 \mathrm{~m} / \mathrm{s}^{2}$.

In this paper, in order to enhance the ability to control and optimal operation of the captain and the crew, to ensure the safety of the vessels at high speed and crosswinds if angles crosswinds too large will directly menace to global stability vessels. This has been very clear recommendations in the stable notice board, if the arm is tilted too large due to weather conditions as well as the angle of the wind direction, the high-speed meaning vessels, sea surface conditions plus... will lead to flip the vessels. Therefore, we give many survey cases for wind angle from $0^{\circ}$ and $30^{\circ}$ in comparison with the direction of the vessel. Six degrees of freedom of the hull is completely fixed during the simulation process.

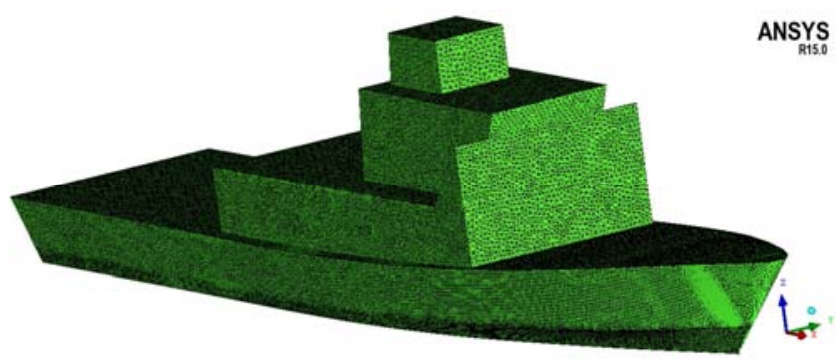

Figure 2. Meshing refinement hull of vessel's superstructure.

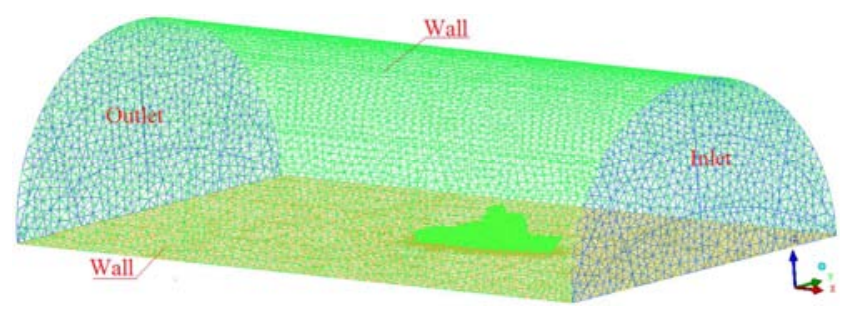

Figure 3. Computational domain mesh of frigate.

\subsection{Meshing and Domain Analysis}

The computational mesh is divided so that the appropriate density depending on the computer configuration, however, the density of different locations should also be considered in a reasonable manner, this is expressed in $[13,15]$. Currently, there is a lot powerful meshing software such as Hypermesh, Gambit... and in fact, Fluent software was previously mainly supported by Gambit meshing, however, due to the development of a strong module on Ansys meshing was developed and built in which is the ICEM. Therefore, in this study, the case survey we conducted by ICEM meshing software.

Overall meshing whole ship is expressed in Figure 3. The mesh of important areas is fine-tuned to accurately capture the free surface and velocity field when simulating as well as accurately calculating variables near the hull area. These fine tuning domains include boundary layer around the hull, the area near the bow and the stern. For high-speed vessels, the mesh is refined is expanded and tweaked level improved to keep the accuracy that can be acceptable.

\section{Results and Discussion}

By iterative analysis method of the time step, the result of the resistance value and the corresponding drag coefficient reaches the convergence value. For each case, the average value of converged data is taken as the final result.

The results of the surveyed are shown in Table 2.

Table 2. Table of wind resistance.

\begin{tabular}{lll}
\hline Wind direction & $\begin{array}{l}\text { Wind area on } \\
\text { the vessel }\left(\mathbf{m}^{\mathbf{2}}\right)\end{array}$ & Resistance in the $\mathbf{x}-\operatorname{direction} \mathbf{( N )}$ \\
\hline $0^{0}$ & 73 & -6682.8 \\
$5^{0}$ & 91.3 & -8442.8 \\
$10^{0}$ & 110.6 & -10224.3 \\
$15^{0}$ & 122 & -12136.6 \\
$20^{0}$ & 132.7 & -14126.8 \\
$25^{0}$ & 145.9 & -16291.3 \\
$30^{0}$ & 158.4 & -18553.6 \\
\hline
\end{tabular}

In this study, the aimed to assess the effect of the wind to the vessels, the authors conducted comparing the area of wind direction and ship resistance according to $\mathrm{x}$ direction with a wind speed of $14.5 \mathrm{~m} / \mathrm{s}$ in many different angle wind directions from $0^{0}$ to $30^{\circ}$. Through the results obtained, we found that the area of wind angle at $30^{\circ}$ is 2.17 times higher than the $0^{0}$ wind direction, however, the resistance increased by 2.78 times. The influence of the wind direction to the resistance is shown in the following graph:

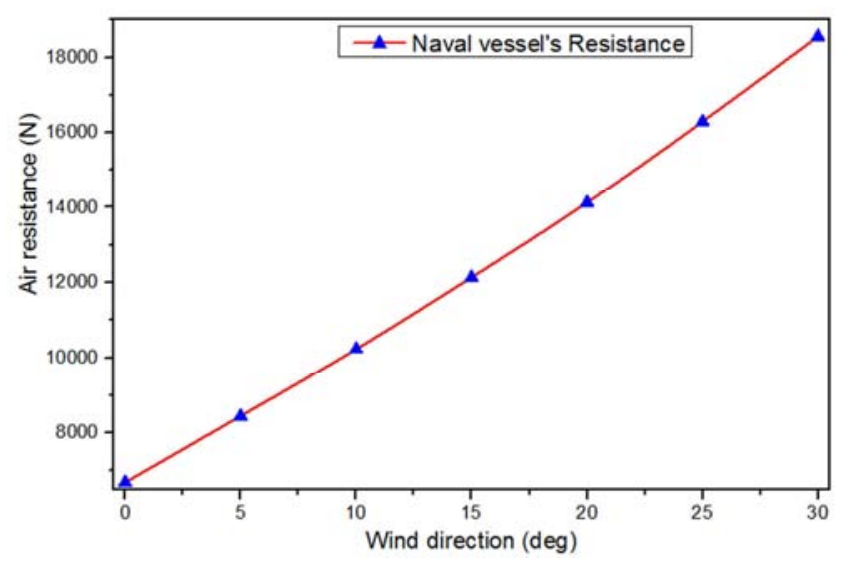

Figure 4. Diagram of wind angle direction-resistance. 
Therefore, in the next study more deeply we can perform simulations in many different velocity cases as well as to generally evaluate the wind levels and comparison with testing and whether standards according to IMO standards.

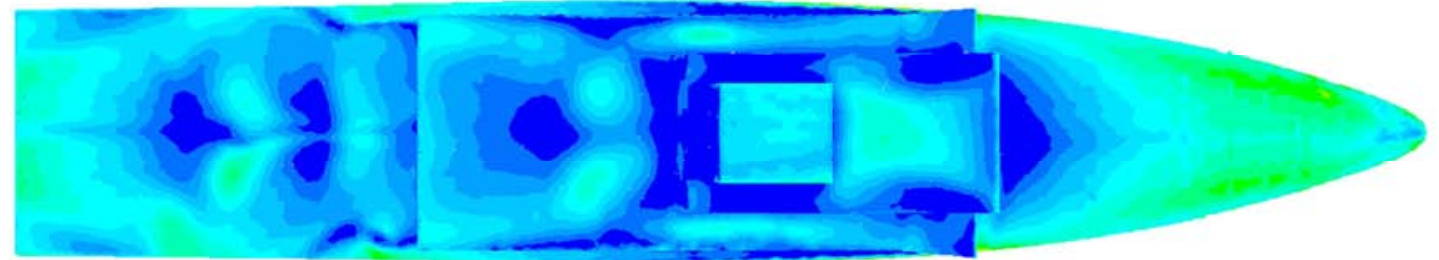

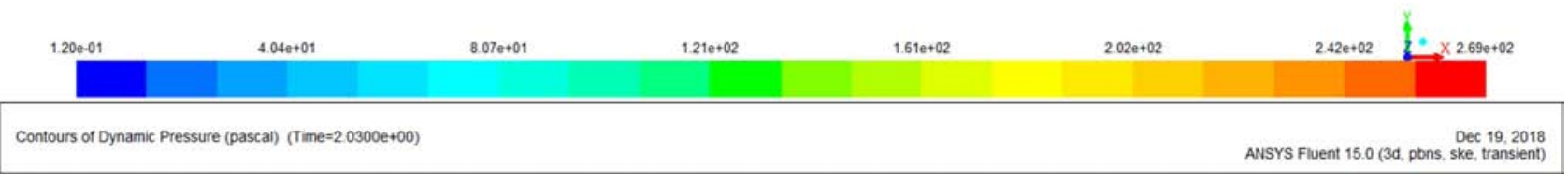

(a)

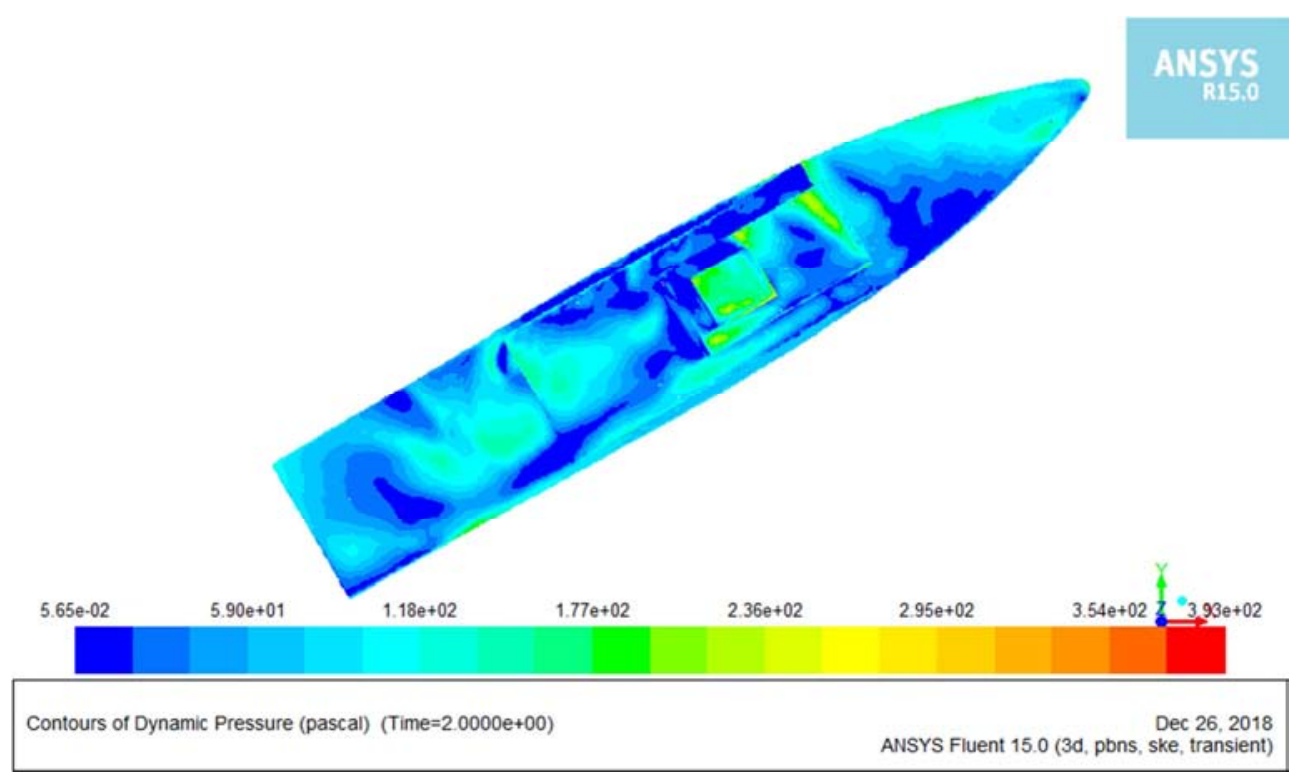

(b)

Figure 5. Dynamic pressure distribution at the impact on the deck. (a) with $0^{0}$ wind direction; (b) with $30^{\circ}$ wind direction.

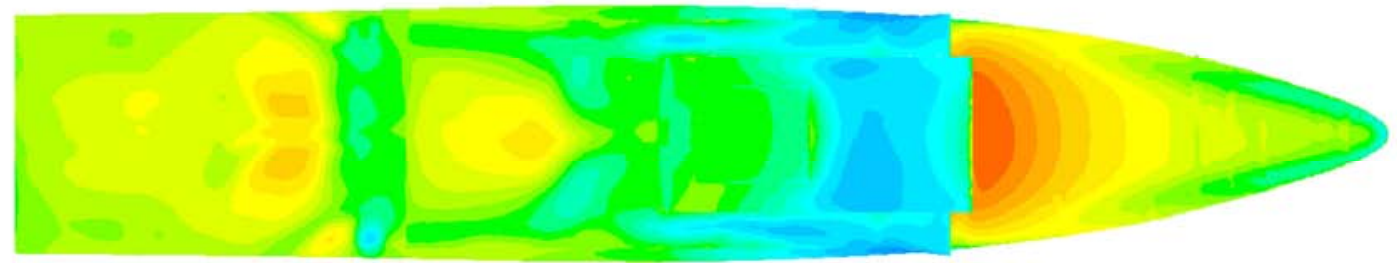

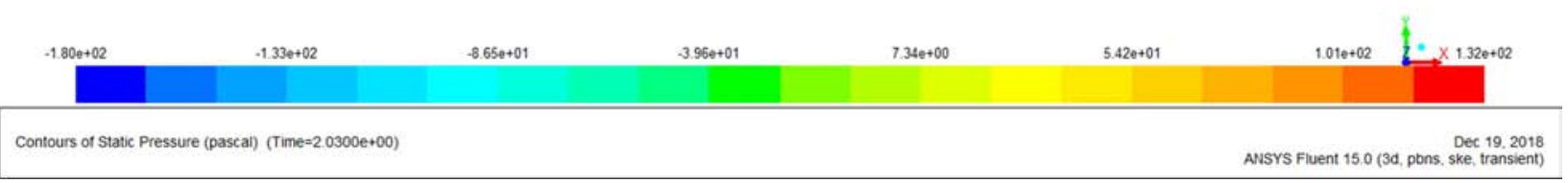




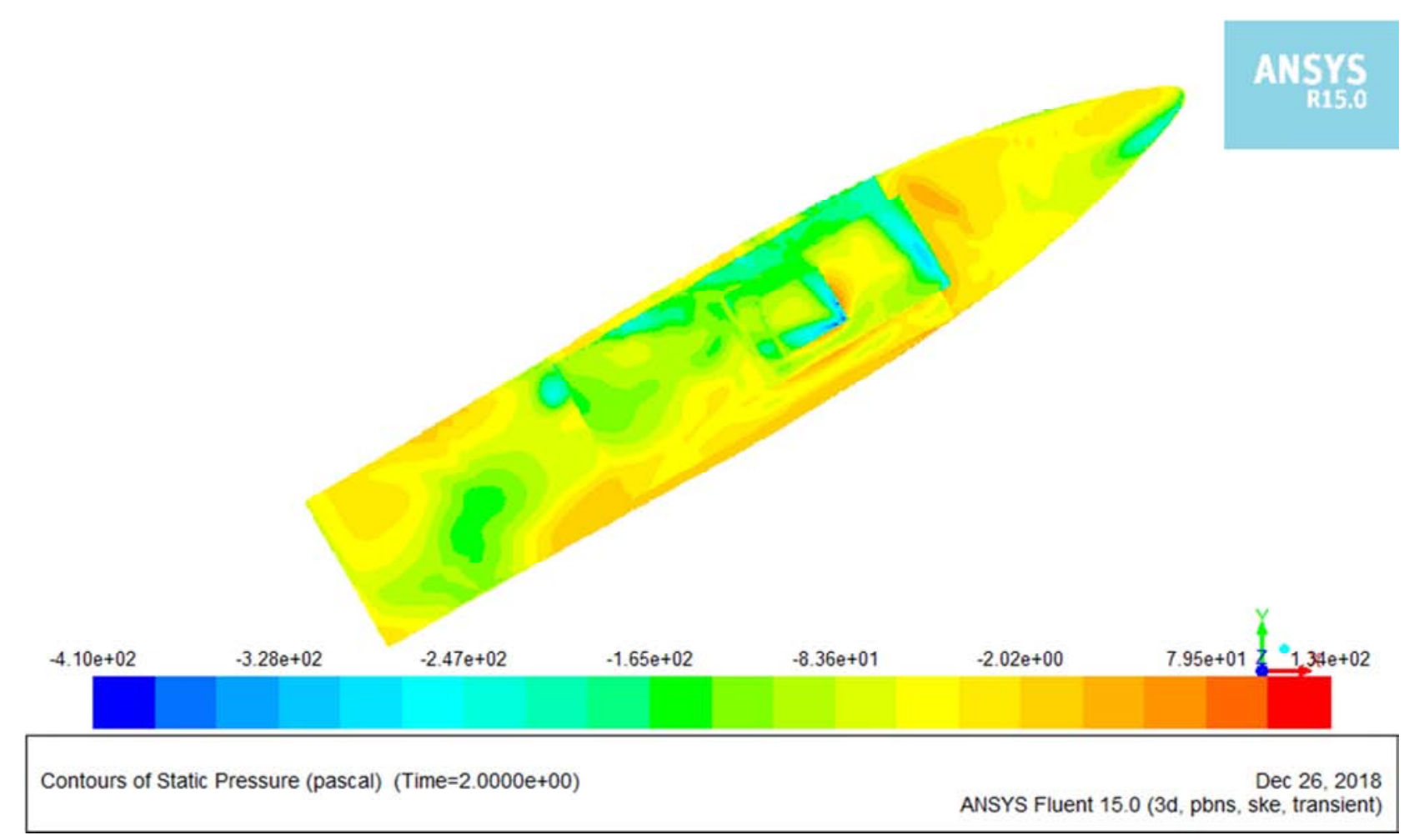

(b)

Figure 6. Static pressure distribution at the impact on the deck with $0^{\circ}(a)$ with $0^{\circ}$ wind direction; (b) with $30^{\circ}$ wind direction.

The distribution of the flow around the ship

Through simulation we obtained images cross the lines around the hull. By studying the direction and shape of the flow of air around the hull, it is possible to study and evaluate the effect of the air flow field on the hull. The turbulent flow that appears around the ship is an important factor that causing the increase in ship's resistance. The cross lines around the vessel at the cross section center vessel are shown in Figure 7.

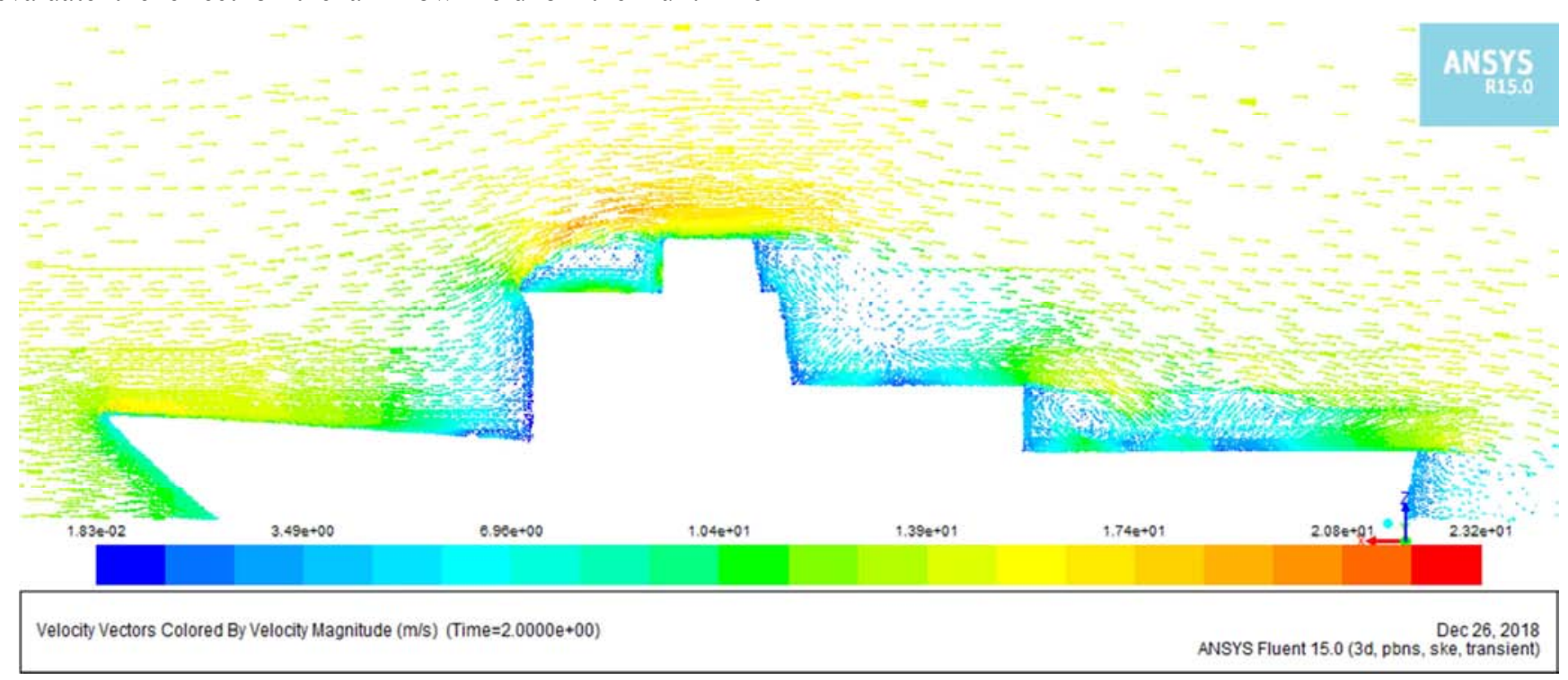

Figure 7. Velocity vector at the longitudinal section of the center vessel with $0^{0}$ direction.

Through Figure 7, we find that the lines distributed near the bow are relatively smooth and steady, the stern and upper sections appear more eddy lines. Clearly, the color distribution image, despite the difference in flow rate, a vortex in the tail, however, we see not too big, but the increase in this flow and vortex speed increases the level of turbulence, leading to the increase in resistance on the vessel.

- Distributing pressure around the hull

Pressure distribution around the vessel with different survey cases is shown in Figure 8. 


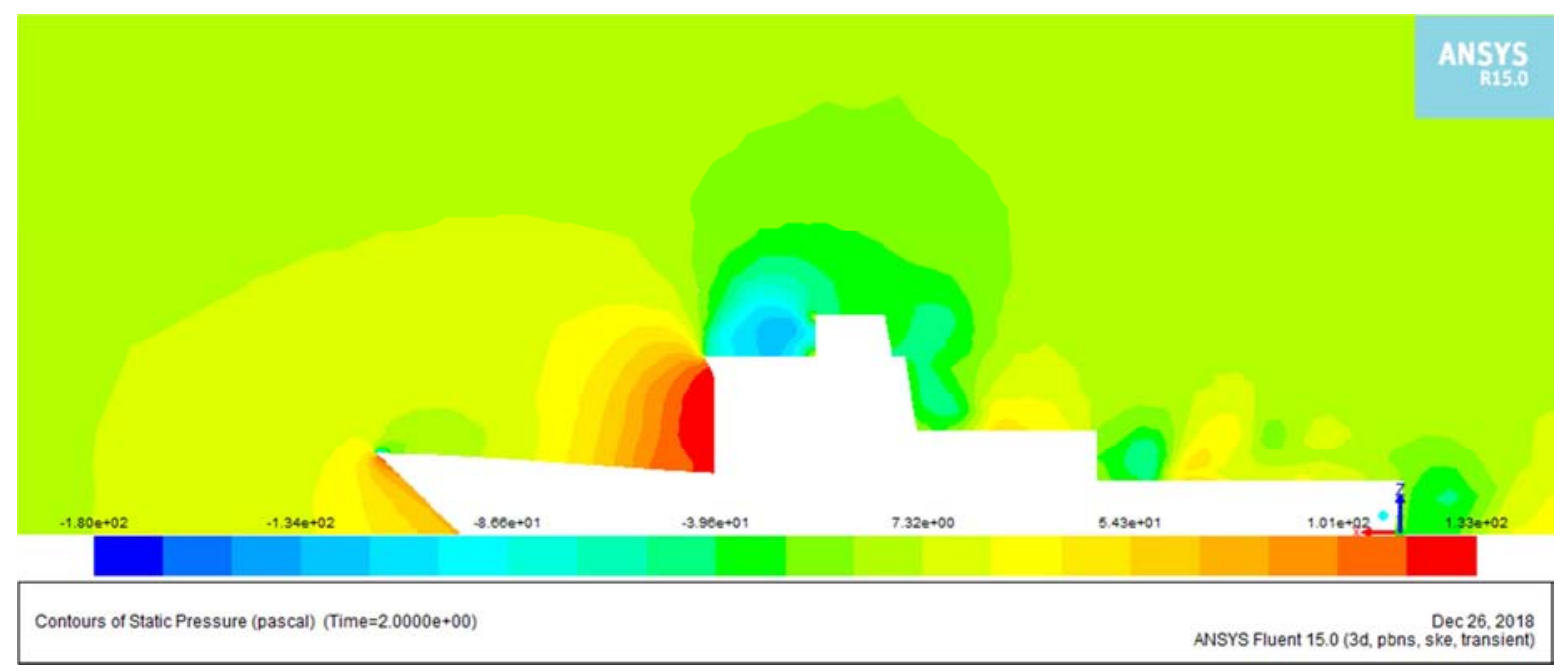

Figure 8. Static pressure distribution in the longitudinal section of the center with $0^{0}$ direction.
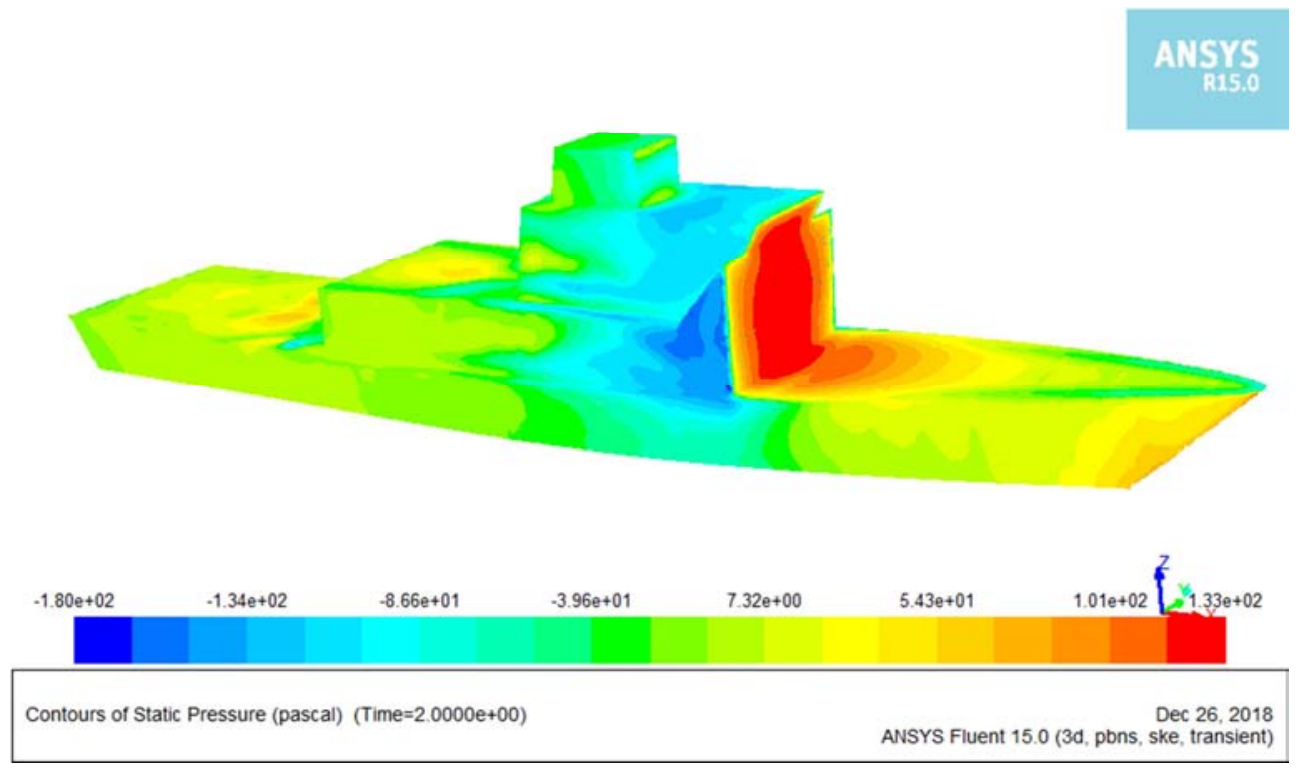

(a)

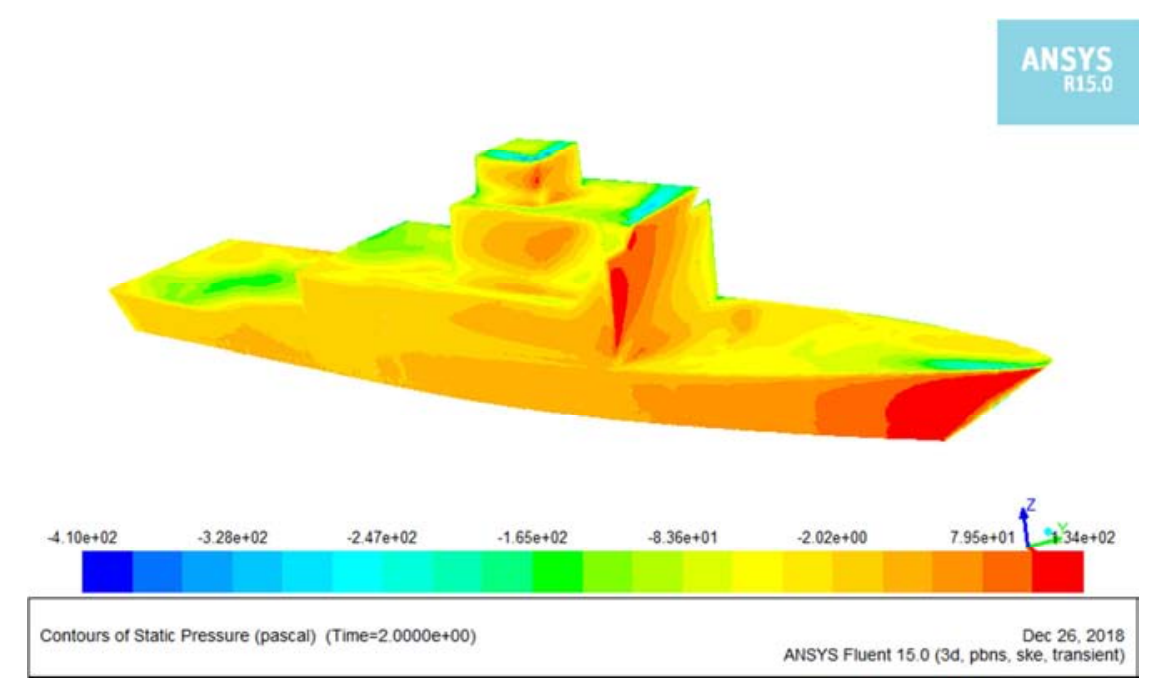

(b)

Figure 9. Distribution of static pressure throughout the ship (a) with $0^{\circ}$ wind direction; (b) with $30^{\circ}$ wind direction. 


\section{Conclusion}

1. CFD numerical simulation method has been applied to assess the effect of the wind angle direction to the resistance of naval vessels in calm water conditions.

2. Results of this study are the basis to expand research for different velocities, different angles of the wind direction and give an assessment on the effects of horizontal and vertical tilt angle when the wind's impact to the stability of the vessel as well as accident stability.

3. The development of technology as well as the application of optimal algorithms to analysis the optimal wind direction angle selection.

4. Research results help designers improve superstructure so that they can achieve optimal hull shape of the ship.

\section{Disclosure Statement}

The authors declare that they have no competing interests

\section{References}

[1] S. M. Mousaviraad. CFD prediction of ship response to extreme winds and_or waves 2010.

[2] M. V. K. Mahesh. Large eddy simulation of propeller crashback 2010.

[3] A. Bakica, I. Gatin, V. Vukčević, H. Jasak, and N. Vladimir. Accurate assessment of ship-propulsion characteristics using CFD 2019, 175, p. 149-162.

[4] N. J. van der Kolk, J. A. Keuning, and R. H. M. Huijsmans. Part 1: Experimental validation of a RANS-CFD methodology for the hydrodynamics of wind-assisted ships operating at leeway angles 2019, 178, p. 375-387.

[5] B. R. R. Ram, S. Surendran, and S. K. Lee. Computer and experimental simulations on the fin effect on ship resistance 2014, 10, 2, p. 122-131.

[6] G.-Y. Kong, Y.-S. Lee, and S.-M. Lee. A Study on the Modeling of Transitional Lateral Force Acting on the Berthing Ship by CFD 2004, Vol. 18 p. 1196-1202.

[7] J. Wang, H. Yu, Y. Zhang, and X. Xiong. CFD-based method of determining form factor $\mathrm{k}$ for different ship types and different drafts $2016,15,3$, p. 236-241.

[8] D. Rui, H. De-bo, and Y. L. e. al. Research on factors of a flow field affecting catamaran resistance calculation 2011, 32 (2), p. 141-147.

[9] N. V. He, K. Mizutani, and Y. Ikeda. Reducing air resistance acting on a ship by using interaction effects between the hull and accommodation 2016, 111, p. 414-423.

[10] N. D. Hai, V. V. Tan, and N. N. Dam. Analysis, simulation the waves around the ship and ship hull resistance calculations using CFD methods 2018, No 2 (61), p. 53-59.

[11] J. Jachowski. Assessment of ship squat in shallow water using CFD 2008, 8 (1), p. 27-36.

[12] B. Neil et al. The Specialist Committee on Powering Performance Prediction 2005.

[13] Fluent Totorial Guide 2003.

[14] C. T, S. F, and B. S. et al. Numerical investigation of the seakeeping behavior of a catamaran advancing in regular head waves $2011,38(16)$, p. 1806-1822.

[15] Fluent 6_0 Tuturial Guide_Volume 22001. 